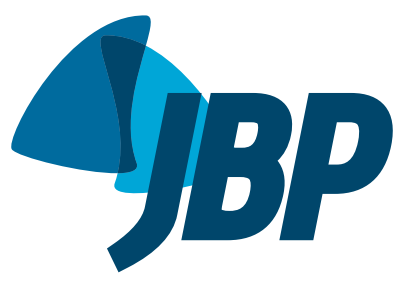

\title{
The Quebec Sleep Questionnaire on quality of life in patients with obstructive sleep apnea: translation into Portuguese and cross-cultural adaptation for use in Brazil
}

\author{
José Tavares de Melo Júnior ${ }^{1}$, Rosemeri Maurici, ${ }^{1,2}$, \\ Michelle Gonçalves de Souza Tavares ${ }^{3}$, Marcia Margareth Menezes Pizzichini ${ }^{1,4}$, \\ Emilio Pizzichini1,2,5
}

1. Programa de Pós-Graduação em Ciências Médicas, Universidade Federal de Santa Catarina - UFSC Florianópolis (SC) Brasil.

2. Núcleo de Pesquisa em Asma e Inflamação das Vias Aéreas - NUPAIVA - Universidade Federal de Santa Catarina, Florianópolis (SC) Brasil.

3. Universidade do Sul de Santa Catarina Unisul - Florianópolis (SC) Brasil.

4. Departamento de Clínica Médica, Universidade Federal de Santa Catarina - UFSC - Florianópolis (SC) Brasil.

5. Departamento de Pneumologia, Universidade Federal de Santa Catarina - UFSC - Florianópolis (SC) Brasil.

Submitted: 30 May 2016.

Accepted: 26 February 2017

\begin{abstract}
Objective: To translate the Quebec Sleep Questionnaire (QSQ), a specific instrument for the assessment of quality of life in patients with sleep obstructive apnea, into Portuguese and to create a version that is cross-culturally adapted for use in Brazil. Methods: The Portuguese-language version was developed according to a rigorous methodology, which included the following steps: preparation; translation from English into Portuguese in three versions; reconciliation to a single version; back-translation of that version into English; comparison and harmonization of the back-translation with the original version; review of the Portuguese-language version; cognitive debriefing; text review; and arrival at the final version. Results: The Portuguese-language version of the QSO for use in Brazil had a clarity score, as measured by cognitive debriefing, ranging from 0.81 to 0.99 , demonstrating the consistency of translation and cross-cultural adaptation processes. Conclusions: The process of translating the QSQ into Portuguese and creating a version that is cross-culturally adapted for use in Brazil produced a valid instrument to assess the quality of life in patients with obstructive sleep apnea.
\end{abstract}

Study carried out at Hospital Universitário Polydoro Ernani de São Thiago,

Universidade Federal de Santa Catarina UFSC - Florianópolis (SC) Brasil.

\section{INTRODUCTION}

Obstructive sleep apnea (OSA) can be diagnosed on the basis of 5 or more predominantly obstructive respiratory events per hour during polysomnography. These events should be accompanied by signs and symptoms, such as heavy snoring, daytime sleepiness, sudden awakenings with a feeling of suffocation, and apneas observed by others. Alternatively, the occurrence of more than 15 obstructive respiratory events per hour meets the diagnostic criterion even in the absence of signs and symptoms. ${ }^{(1)}$

OSA represents more than $85 \%$ of all causes of sleep-disordered breathing. ${ }^{(2)}$ In a population-based study conducted in the city of São Paulo, Brazil, the prevalence of OSA was $32.8 \%$, ${ }^{(3)}$ bringing the magnitude of this problem to light. With regard to financial impact, in the United States, the annual cost only for treating medical problems caused by OSA is estimated at 3.4 billion dollars. ${ }^{(4)}$

Studies have demonstrated that OSA has a strong relationship with systemic arterial hypertension, ${ }^{(5)}$ changes in glucose metabolism, ${ }^{(6)}$ cardiovascular diseases, ${ }^{(7)}$ and respiratory diseases, such as asthma and COPD. ${ }^{\left({ }^{8}\right)}$ In addition, excessive daytime sleepiness, fatigue, irritability, and personality changes have also been attributed to intermittent oxyhemoglobin desaturations and to the chronic sleep deprivation caused by sleep fragmentation. ${ }^{(9)}$

All of the above changes can lead to decreased quality of life. While studies overvalue the apnea-hypopnea index (AHI) as an outcome measure, the effect of OSA on quality of life is, curiously, seldom mentioned. However, there is a poor correlation between OSA patient-reported quality of life and the AHI, making it inappropriate to use the AHI as the sole outcome measure. ${ }^{(10)}$ Therefore, it seems reasonable that quality-of-life measurement via a specific questionnaire should be considered, which would allow it to be used in epidemiological studies in different regions and in clinical trials. In addition, administering this type of instrument to patients would enable a more reliable analysis of short-, medium-, and long-term effects of a given treatment.

One of the most commonly used generic quality-of-life questionnaires is the Medical Outcomes Study 36 -item Short-Form Health Survey, which has been adapted for use in Brazil(11) and has been used in studies of OSA. ${ }^{(12)}$ However, although the use of generic tools facilitates comparisons across chronic diseases, these tools do

Correspondence to:

José Tavares de Melo Júnior. Núcleo de Pesquisa em Asma e Inflamação das Vias Aéreas (NUPAIVA), Hospital Universitário da UFSC, Campus Universitário, Trindade,

CEP 88040-970, Florianópolis, SC, Brasil.

Tel./Fax: 5548 3234-7711. E-mail: josetavaresj@@hotmail.com

Financial support: None. 
not assess the most important specific aspects of a particular disease to the patient. ${ }^{(13)}$ In addition, generic instruments may not be able to detect the effects of interventions or treatments. ${ }^{(14)}$ To that end, there is a need for specific validated questionnaires, such as the Quebec Sleep Questionnaire (QSQ), ${ }^{(15)}$ which is one of the major instruments for assessing quality of life in OSA patients. Originally designed in French, the QSQ was translated by its authors from French into English and was shown to have excellent psychometric properties. ${ }^{(15)}$ At the time, the minimal clinically important differences for each domain were also determined: 1.8 points for daytime sleepiness; 2.0 points for diurnal symptoms; 1.5 points for nocturnal symptoms; 1.1 points for emotions; and 2.5 points for social interactions. Subsequently, the QSQ was translated into Spanish and adapted for use in Spain, ${ }^{(16)}$ and this Spanish-language version was adequately tested for psychometric properties. ${ }^{(17)}$ In comparison with other instruments that are also specific for OSA, such as the Calgary Sleep Apnea Quality of Life Instrument (SAQLI), ${ }^{(18)}$ the QSQ has some characteristics that should be observed and that make it advantageous. While the SAQLI (56 questions) takes longer to complete, has to be administered by an interviewer, and, in particular, has a "symptoms" domain that is individualized, which may allow interference from the patient, ${ }^{(19)}$ the QSQ is shorter and has standardized items, which makes it more appropriate for large and long-term studies. ${ }^{(20)}$ In contrast, the Maugeri Obstructive Sleep Apnea Syndrome questionnaire was developed to assess the physical and psychological impact of OSA, with an emphasis on adherence to continuous positive airway pressure treatment. ${ }^{(21)}$ It is of note that the questionnaire does not include questions about nocturnal symptoms. ${ }^{(21)}$ Another specific instrument that is widely used in research and clinical practice is the Epworth Sleepiness Scale (ESS). ${ }^{(22,23)}$ However, the ESS is not aimed at measuring quality of life and refers specifically to the "sleepiness" domain.

To date in Brazil, no specific instruments for assessing quality of life in OSA patients have been developed, nor have any such instruments been adapted for use in the country. Therefore, the objectives of the present study were to translate the QSQ into Portuguese and to create a version that is cross-culturally adapted for use in Brazil.

\section{METHODS}

\section{Description of the QSQ}

- The QSQ is an instrument comprising 32 items that assess the impact of apnea on five distinct domains: daytime sleepiness; diurnal symptoms; nocturnal symptoms; emotions; and social interactions. Each domain consists of 4 to 10 items that are rated on a 1- to 7-point Likert scale. The results are expressed as the mean score for each separate domain. Higher scores indicate milder symptoms. The items within each domain are listed below: Daytime sleepiness: items $7 ; 16 ; 20 ; 27 ; 31 ;$ and 32

- Diurnal symptoms: items $1 ; 10 ; 11 ; 14 ; 17 ; 18$ 19; 23, 26; and 29

- Nocturnal symptoms: items $4 ; 9 ; 21 ; 22 ; 25$; 28; and 30

- Emotions: items 5; 6; 8; 15; and 24

- Social interactions: items 2; 3; 12; and 13

Item 32, which refers to the act of driving an automobile, should be left blank if the patient does not drive, and the mean score for the "daytime sleepiness" domain should be calculated from the remaining five items.

\section{Design}

This was a methodological study involving the translation of the QSQ into Portuguese and the creation of a version that is cross-culturally adapted for use in Brazil. The steps of the cross-cultural adaptation process, steps that can also be found in other publications, (24-26) were performed in strict accordance with internationally accepted guidelines ${ }^{(27)}$ and are summarized as follows: 1) preparation: researchers' meeting aimed at planning the study and contacting with the developer of the QSQ to obtain permission to use the instrument; 2) forward translation: three health care professionals carried out three independent forward translations of the QSQ from English into Portuguese; 3) reconciliation: reconciliation of the three forward translations into a single forward translation, performed by the translators; 4) backtranslation: back-translation of the single reconciled version into English; 5) comparison and harmonization: comparison conducted by the authors between the back-translation and the original version of the QSQ in order to detect potential discrepancies; 6) review of the Portuguese-language version of the QSQ by experts; 7) cognitive debriefing: process of testing the translated questionnaire on the target population in order to check understandability of the questions. Twenty-five patients were interviewed, all of whom were literate, were over 18 years of age, had a diagnostic suspicion of OSA-snoring, witnessed apneas, and excessive daytime sleepiness-were treated as outpatients, and had clinical indications for polysomnography. The diagnosis of OSA was subsequently confirmed by baseline overnight polysomnography, which was performed in a certified sleep laboratory, when the AHI was greater than or equal to 15 events/h or when the $\mathrm{AHI}$ was greater than or equal to 5 events/h in patients who reported other symptoms, such as awakening due to gasping, daytime sleepiness, fatigue, cognitive changes, and nonrestorative or fragmented sleep. ${ }^{(28)}$ The patients were first asked to complete the translated questionnaire itself. Since the QSQ is a self-administered questionnaire, its translated version was completed by the participants themselves without the assistance of the attending physician. Then, in order to cognitively debrief the translated questionnaire, another instrument was completed. At this point, the participants were told that they should rate their understanding of each of the 32 previously answered questions on a 1- to 10-point Likert scale. 
Scores between 1 and 4 were defined as indicating confusing wording; scores between 5 and 7 were defined as indicating unclear wording; and scores between 8 and 10 were defined as indicating clear wording. ${ }^{(29)}$ The clarity score for each item was obtained by calculating the mean of the scores attributed by the patients to each of the items. The items whose means were less than 0.4 should be replaced. The items whose means were less than 0.8 should be reformulated. Finally, the items that had means $\geq 0.8$ were considered appropriate in terms of understandability and were maintained; 8) review: full-text review by a Portuguese teacher; and 9) final version: preparation of the final version of the symptom-specific questionnaire for assessing quality of life in OSA patients. The study protocol, including the final version of the written informed consent form, was submitted to and approved by the Human Research Ethics Committee of the Federal University of Santa Catarina.

Participation in the present study was voluntary, and all participants, who were recruited at a private clinic in the city of Florianópolis, Brazil, gave written informed consent before answering any questions.

Patient demographics and clinical data were characterized with descriptive statistics, and the results were expressed as mean and standard deviation.

\section{RESULTS}

Of the 25 patients interviewed for cognitive debriefing, 3 were excluded because they were lost to follow-up. Of the remaining 22 patients, 16 were male. Patient age ranged from 26 to 65 years. The mean body mass index (BMI) was $28.5 \mathrm{~kg} / \mathrm{m}^{2}$, being $29.0 \pm 5.0$ $\mathrm{kg} / \mathrm{m}^{2}$ for males and $27.1 \pm 2.3 \mathrm{~kg} / \mathrm{m}^{2}$ for females.

Table 1. Patient distribution by demographic characteristics and polysomnography data. ${ }^{a}$

\begin{tabular}{lc}
\multicolumn{1}{c}{ Characteristic } & Result \\
Age, years & $44.68 \pm 10.75$ \\
Male gender & $16(72.7)$ \\
Level of education $\leq$ high school & $5(22.7)$ \\
Body mass index, $\mathrm{kg} / \mathrm{m}^{2 *}$ & $28.5 \pm 4.4$ \\
Neck circumference, $\mathrm{cm}$ & $39.3 \pm 3.6$ \\
AHI, events/h & $23.4 \pm 26.7$ \\
Arousal index, events/h & $27.5 \pm 13.5$ \\
\hline
\end{tabular}

AHI: apnea-hypopnea index. aValues expressed as $n$ (\%) or as mean \pm SD.
The mean neck circumference for males and females was, respectively, $40.6 \pm 3.4 \mathrm{~cm}$ and $36.0 \pm 1.41$ $\mathrm{cm}$. Polysomnography revealed a mean $\mathrm{AHI}$ of 23.4 \pm 26.7 events/h (range: 0.0-89.7 events/h; Table 1 ). The results of the Portuguese-language version of the QSQ administered to the participants are summarized in Table 2.

In the forward and back-translation steps, no questions or corrections were raised. The review carried out by the expert committee did not point out any grammatical or conceptual errors. Similarly, there were no difficulties in translating or adapting words related to the domains. However, some English idioms and phrases were a matter of review and discussion. For instance, in the step in which the back-translated version was compared with the original version, the author of the QSQ raised two questions regarding differences from the initial concept. The first referred to the fact that item 23 differed between the back-translated version and the original English-language version; however, the author agreed to the cross-cultural adaptation for use in Brazil, because our translation was more faithful to the original French-language version. Therefore, "feeling that you lack energy" read "feeling that you are exhausted (worn-out)" in the back-translation, and, as already said, was accepted by the author of the QSQ. The second question referred to the response choices in the Likert scale for items 10 to 15: the backtranslation of these response choices was "excessively; often/moderately to often; moderately; a little; barely; and not at all". The author of the QSQ explained that these response choices expressed quantity and time and that he would rather they expressed only quantity (as in the original French-Canadian version). As a result, the response choices in the Likert scale were changed to "quantidade muito grande; quantidade grande; moderada a grande quantidade; moderada quantidade; pequena a moderada quantidade; pequena quantidade; e nada".

After the changed version of the back-translation was approved by the author of the QSQ, an expert committee met to evaluate the Portuguese-language version of the questionnaire in order to detect errors, offer suggestions, and evaluate its content and structure. The review carried out by the expert committee did not point out any grammatical or conceptual errors. Grammatical corrections were made also by the

Table 2. Scores in each domain of the Portuguese-language version of the Quebec Sleep Questionnaire by apneahypopnea index.

\begin{tabular}{|c|c|c|c|c|c|}
\hline \multirow{3}{*}{ Domain } & \multicolumn{4}{|c|}{ Group } & \multirow[t]{3}{*}{$p^{*}$} \\
\hline & \multicolumn{2}{|c|}{$\begin{array}{c}\text { AHI }<5 \text { events } / \mathrm{h} \\
n=6\end{array}$} & \multicolumn{2}{|c|}{$\begin{array}{c}\text { AHI } \geq 5 \text { events } / \mathrm{h} \\
n=16\end{array}$} & \\
\hline & Score $^{a}$ & Range & Score $^{a}$ & Range & \\
\hline Daytime sleepiness & $5.5 \pm 1.6$ & $2.7-6.7$ & $5.6 \pm 1.4$ & $2.8-7.0$ & 0.84 \\
\hline Diurnal symptoms & $4.9 \pm 1.7$ & $2.2-6.6$ & $4.9 \pm 1.4$ & $2.3-6.7$ & 0.95 \\
\hline Nocturnal symptoms & $4.7 \pm 1.5$ & $3.3-6.4$ & $4.5 \pm 1.4$ & $1.7-6.1$ & 0.73 \\
\hline Emotions & $4.8 \pm 1.5$ & $3.0-6.6$ & $4.7 \pm 1.4$ & $2.4-6.8$ & 0.87 \\
\hline Social interactions & $3.0 \pm 1.1$ & $1.8-4.5$ & $3.9 \pm 1.2$ & $6.0-1.6$ & 0.12 \\
\hline
\end{tabular}

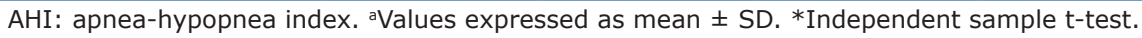


Portuguese-language expert, and the questionnaire version intended for use during cognitive debriefing was then produced.

To ensure that the entire translated instrument was easy to understand, cognitive debriefing involved an item-by-item analysis. The instrument was reviewed by discussing the response findings. No item needed to be reformulated, the minimum score being 0.81 and the maximum score being 0.99 (Figure 1 ). Therefore, the version tested during cognitive debriefing was accepted without changes, after full agreement by all researchers (Appendix is available online at http:// jornaldepneumologia.com.br/detalhe_anexo.asp?id=55).

\section{DISCUSSION}

In the present study, a specific instrument for measuring quality of life in OSA patients, the QSQ, was cross-culturally adapted for use in Brazil. Cognitive debriefing results showed that the level of understandability of all items of the instrument was appropriate. This finding is of great relevance because it demonstrates the consistency of the translation and cross-cultural adaptation process. However, although all items had a clarity score greater than 0.8 , when we consider the performance of item 13-"Você tem se sentido culpado em seu relacionamento com familiares ou amigos íntimos?"-we observe that this item had the lowest mean score of all $(0.81)$. We believe that, rather than reflecting patient difficulty in understanding, this finding may have reflected the essentially subjective content of the question.

The process of cross-cultural adaptation of a questionnaire includes not only a translated version that is conceptually equivalent to the original instrument but also one that is culturally acceptable in the country in which it will be used. Therefore, in order to achieve technical and semantic equivalence between the source and target language versions, the present study was conducted according to recommendations in the literature. ${ }^{(27,30)}$ By ensuring this equivalence, distortions that could compromise the instrument's psychometric properties that have been documented in previous studies are avoided. ${ }^{(31)}$

We chose the QSQ because it is a validated specific self-administered questionnaire that is easy to complete and is structured in different domains. In addition, the QSQ has the characteristic of being responsive to changes induced by therapeutic interventions. ${ }^{(32)}$ In recent years, various studies have used the QSQ to measure quality of life in OSA patients. For instance, the QSQ was useful in revealing improved quality of life in OSA patients undergoing continuous positive airway pressure treatment. ${ }^{(33)}$ In patients with mild positional OSA who wore an electronic sleep position training device, quality of life was found to improve significantly. ${ }^{(34)}$ In another study, the use of the QSQ and the ESS made it possible to demonstrate that OSA patients may underestimate their sleepiness when this symptom is measured by the ESS. ${ }^{(35)}$ More recently, in a systematic review of various questionnaires for use in OSA patients, ${ }^{(36)}$ the QSQ was one of those recommended for assessing OSA patients in clinical practice, notably because of its content validity.

We acknowledge that one limitation of the QSQ is that, since it is a specific standardized instrument, individual choices may be restricted, and, therefore, the instrument accuracy in terms of its responsiveness

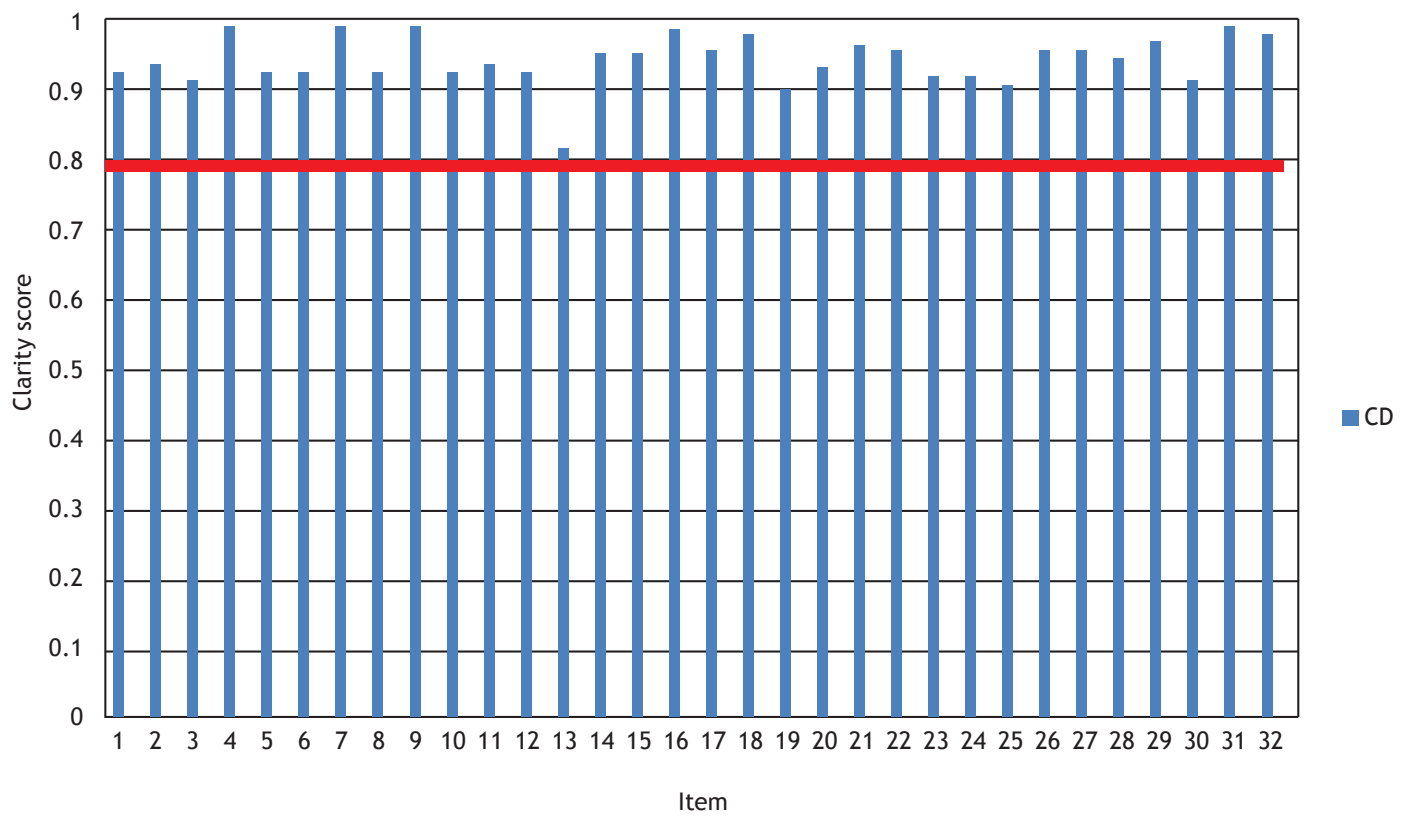

Figure 1. Clarity of each item of the Portuguese-language version of the Quebec Sleep Questionnaire. The blue bars represent the clarity scores obtained during cognitive debriefing. The red line indicates the cut-off point at which an item is considered clear: 0.80 . The figure shows that all questionnaire items were considered clear during cognitive debriefing. CD: cognitive debriefing 
to treatment may be affected. With regard to our study design, one could question the choice to maintain patients with complaints of snoring and nonrestorative sleep, among other complaints, but with an $\mathrm{AHI}<5$ events/h. As to that, we took care to conduct a parallel cognitive debriefing analysis only in those individuals with an $\mathrm{AHI}<5$ events/h and concluded that there was no difference between the cognitive debriefing results. It is of interest that, regarding the scores on the Portuguese-language version of the QSQ itself, no significant differences were also found in any of the domains between individuals with an $\mathrm{AHI}<5$ events/h and those with an $\mathrm{AHI} \geq 5$ events/h. In addition, we emphasize that our objective was the cross-cultural adaptation of the QSQ, which is a complementary process in the validation of psychometric properties. Since the translation and adaptation process followed a rigorous and recommended methodology, we can infer that the translated instrument retained the properties of the original instrument and is therefore suitable for use in Brazil. Additional studies using the translated instrument may help expand and confirm our observations.

In summary, the QSQ has now been translated into Portuguese and adapted for use in Brazil. We believe that the future use of this version of the QSQ in multicenter epidemiological studies in various regions could make it possible to compare results and to estimate the degree to which sociocultural differences influence the impact that OSA has on the quality of life of populations. It is of note that the QSQ is a single measure of OSA-related quality of life, now available in a Brazilian Portuguese-language version.

\section{ACKNOWLEDGMENTS}

The authors would like to thank the developer of the Quebec Sleep Questionnaire, Dr. Yves Lacasse, for his receptiveness to the present project and his participation when necessary. We would also like to thank Dr. Luciano Nogueira for his valuable participation in the initial translation process.

\section{REFERENCES}

1. American Academy of Sleep Medicine. International Classification of Sleep Disorders. 3rd ed. Darien, IL: American Academy of Sleep Medicine; 2014.

2. Morgenthaler $\mathrm{TI}$, Kagramanov V, Hanak V, Decker PA. Complex sleep apnea syndrome: is it a unique clinical syndrome? Sleep. 2006;29(9):1203-9. https://doi.org/10.1093/sleep/29.9.1203

3. Tufik S, Santos-Silva R, Taddei JA, Bittencourt LR. Obstructive sleep apnea syndrome in the Sao Paulo Epidemiologic Sleep Study. Sleep Med. 2010;11(5):441-6. https://doi.org/10.1016/j.sleep.2009.10.005

4. Kapur V, Blough DK, Sandblom RE, Hert R, de Maine JB, Sullivan $\mathrm{SD}$, et al. The medical cost of undiagnosed sleep apnea. Sleep. 1999;22(6):749-55. https://doi.org/10.1093/sleep/22.6.749

5. Peppard PE, Young T, Palta M, Skatrud J. Prospective study of the association between sleep-disordered breathing and hypertension. N Engl J Med. 2000; 342(19):1378-84. https://doi.org/10.1056/ NEJM200005113421901

6. Punjabi NM, Polotsky VY. Disorders of glucose metabolism in sleep apnea. J Appl Physiol (1985). 2005;99(5):1998-2007. https://doi. org/10.1152/japplphysiol.00695.2005

7. Peker $Y$, Carlson J, Hedner J. Increased incidence of coronary artery disease in sleep apnoea: a long-term follow-up. Eur Respir $J$. 2006;28(3):596-602. https://doi.org/10.1183/09031936.06.00107805

8. loachimescu OC, Teodorescu M. Integrating the overlap of obstructive lung disease and obstructive sleep apnoea: OLDOSA syndrome. Respirology. 2013;18(3):421-31. https://doi.org/10.1111/resp.12062

9. Colt HG, Haas $H$, Rich GB. Hypoxemia vs sleep fragmentation as cause of excessive daytime sleepiness in obstructive sleep apnea. Chest. 1991;100(6):1542-8. https://doi.org/10.1378/chest.100.6.1542

10. Tam S, Woodson BT, Rotenberg B. Outcome measurements in obstructive sleep apnea: beyond the apnea-hypopnea index. Laryngoscope. 2014;124(1):337-43. https://doi.org/10.1002/ lary.24275

11. Laguardia J, Campos MR, Travassos CM, Najar AL, Anjos LA, Vasconcellos MM. Psychometric evaluation of the SF-36 (v.2) questionnaire in a probability sample of Brazilian households: results of the survey Pesquisa Dimensões Sociais das Desigualdades (PDSD), Brazil, 2008. Health Qual Life Outcomes. 2011:9:61. https:// doi.org/10.1186/1477-7525-9-61

12. Ackel-D'Elia C, da Silva AC, Silva RS, Truksinas E, Sousa BS, Tufik S, et al. Effects of exercise training associated with continuous positive airway pressure treatment in patients with obstructive sleep apnea syndrome. Sleep Breath. 2012;16(3):723-35. https://doi.org/10.1007/ s11325-011-0567-0

13. Hopkins C. Patient reported outcome measures in rhinology. Rhinology. 2009;47(1):10-7.
14. Hopkins C, Gillett S, Slack R, Lund VJ, Browne JP. Psychometric validity of the 22-item Sinonasal Outcome Test. Clin Otolaryngol. 2009;34(5):447-54. https://doi.org/10.1111/J.1749-4486.2009.01995.x

15. Lacasse $Y$, Bureau MP, Series F. A new standardised and selfadministered quality of life questionnaire specific to obstructive sleep apnoea. Thorax. 2004;59(6):494-9. https://doi.org/10.1136/ thx.2003.011205

16. Herrejón A, Martínez A, Peris R, Inchaurraga I, Fernández E, Blanquer R. Translation and adaptation to Spanish language of the quality of life questionnaire for sleep apnea-hipopnea syndrome Quebec Sleep Questionnaire [Article in Spanish]. Med Clin (Barc). 2012;138(12):51921. https://doi.org/10.1016/j.medcli.2011.09.020

17. Catalán P, Martínez A, Herrejón A, Chiner E, Martínez-García MÁ Sancho-Chust JN, et al. Internal consistency and validity of the Spanish version of the "Quebec Sleep Questionnaire" quality-oflife questionnaire for obstructive sleep apnea. Arch Bronconeumol. 2012;48(4):107-13. https://doi.org/10.1016/j.arbres.2011.10.011

18. Flemons WW, Reimer MA. Development of a disease-specific health-related quality of life questionnaire for sleep apnea. Am J Respir Crit Care Med. 1998;158(2):494-503. https://doi.org/10.1164/ ajrccm.158.2.9712036

19. Lacasse $Y$, Godbout $C$, Sériès F. Independent validation of the Sleep Apnoea Quality of Life Index. Thorax. 2002;57(6):483-8. https://doi. org/10.1136/thorax.57.6.483

20. Juniper EF, Buist AS, Cox FM, Ferrie PJ, King DR. Validation of a standardized version of the Asthma Quality of Life Questionnaire. Chest. 1999;115(5):1265-70. https://doi.org/10.1378/ chest.115.5.1265

21. Moroni L, Neri M, Lucioni AM, Filipponi L, Bertolotti G. A new means of assessing the quality of life of patients with obstructive sleep apnea: the MOSAS questionnaire. Sleep Med. 2011;12(10):959-65. https://doi.org/10.1016/j.sleep.2011.07.010

22. Johns MW. A new method for measuring daytime sleepiness: the Epworth sleepiness scale. Sleep. 1991;14(6):540-5. https://doi. org/10.1093/sleep/14.6.540

23. Bertolazi AN, Fagondes SC, Hoff LS, Pedro VD, Menna Barreto SS, Johns MW. Portuguese-language version of the Epworth sleepiness scale: validation for use in Brazil. J Bras Pneumol. 2009;35(9):877-83. https://doi.org/10.1590/S1806-37132009000900009

24. Felisbino MB, Steidle LJ, Gonçalves-Tavares M, Pizzichini MM, Pizzichini E. Leicester Cough Questionnaire: translation to Portuguese and cross-cultural adaptation for use in Brazil. J Bras Pneumol. 2014;40(3):213-21. https://doi.org/10.1590/S180637132014000300003

25. Tavares MG, Pizzichini MM, Steidle LJ, Nazário NO, Rocha CC 
The Quebec Sleep Questionnaire on quality of life in patients with obstructive sleep apnea:

translation into Portuguese and cross-cultural adaptation for use in Brazil

Perraro MC, et al. The Asthma Control Scoring System: translation and cross-cultural adaptation for use in Brazil. J Bras Pneumol. 2010;36(6):683-92.

26. Caminha GP, Melo Junior JT, Hopkins C, Pizzichini E, Pizzichini MM SNOT-22: psychometric properties and cross-cultural adaptation into the Portuguese language spoken in Brazil. Braz J Otorhinolaryngol. 2012;78(6):34-9. https://doi.org/10.5935/1808-8694.20120030

27. Wild D, Grove A, Martin M, Eremenco S, McElroy S, VerjeeLorenz A, et al. Principles of Good Practice for the Translation and Cultural Adaptation Process for Patient-Reported Outcomes (PRO) Measures: report of the ISPOR Task Force for Translation and Cultural Adaptation. Value Health. 2005;8(2):94-104. https://doi.org/10.1111/ j.1524-4733.2005.04054.x

28. American Academy of Sleep Medicine. The international classification of sleep disorders: diagnostic and coding manual. 2nd ed. Westchester, IL: American Academy of Sleep Medicine; 2005

29. Melo SI. Coeficiente de atrito: um sistema de avaliação [thesis]. Santa Maria: Universidade Federal de Santa Maria; 1994. p. 94-9.

30. Guillemin F, Bombardier C, Beaton D. Cross-cultural adaptation of health-related quality of life measures: literature review and proposed guidelines. J Clin Epidemiol. 1993;46(12):1417-32. https://doi. org/10.1016/0895-4356(93)90142-N
31. Reichenheim ME, Moraes CL. Operationalizing the cross-cultura adaptation of epidemiological measurement instruments [Article in Portuguese]. Rev Saude Publica. 2007;41(4):665-73. https://doi org/10.1590/S0034-89102006005000035

32. Randerath WJ, Sanner BM, Somers VK, editors. Sleep apnea: current diagnosis and treatment. Basel: Karger; 2006.

33. Martínez-Garcia MÁ, Chiner E, Hernández L, Cortes JP, Catalán $P$, Ponce $S$, et al. Obstructive sleep apnoea in the elderly: role of continuous positive airway pressure treatment. Eur Respir J. 2015 46(1):142-51. https://doi.org/10.1183/09031936.00064214

34. Eijsvogel MM, Ubbink R, Dekker J, Oppersma E, de Jongh FH, van der Palen J, et al. Sleep position trainer versus tennis ball technique in positional obstructive sleep apnea syndrome. J Clin Sleep Med. 2015;11(2):139-47. https://doi.org/10.5664/jcsm.4460

35. Leclerc G, Lacasse $Y$, Page D, Sériès F. Do obstructive sleep apnea syndrome patients underestimate their daytime symptoms before continuous positive airway pressure treatment? Can Respir J 2014;21(4):216-20. https://doi.org/10.1155/2014/681952

36. Abma IL, van der Wees PJ, Veer V, Westert GP, Rovers M Measurement properties of patient-reported outcome measures (PROMs) in adults with obstructive sleep apnea (OSA): A systematic review. Sleep Med Rev. 2016;28:18-31. https://doi.org/10.1016/]. smrv.2015.07.006 